\title{
A análise das condições pessoais do interessado no reconhecimento da necessidade no benefício de prestação continuada $^{1}$
}

José Wagner Rodrigues Longuinho²

\section{RESUMO}

Ao realizar o trabalho sobre o tema proposto, inicialmente faz-se uma breve abordagem acerca do conceito de Seguridade Social. Em seguida, é feita uma explanação sobre o Benefício de Prestação Continuada, como parte das medidas adotadas pelo Estado no âmbito da Assistência Social, conceituando-o, indicando sua previsão legal e apresentando uma breve introdução na temática referente ao critério de aferição da miserabilidade, enfoque deste trabalho. Para finalizar, é feita uma análise descritiva da jurisprudência pátria no âmbito do Supremo Tribunal Federal, acerca do requisito da miserabilidade, visto o amplo desenvolvimento crítico-doutrinário envolvendo a temática, e como se desenvolveu essa discussão, até se chegar a um pensamento flexibilizado desse requisito em questão. Após essa explanação, conclui-se, analisando a importância do surgimento de novas medidas legislativas, com a finalidade de melhoraria de vida das pessoas com deficiência, e da pessoa idoso com mais de 65 anos no seio da sociedade em igualdade de condições com as demais pessoas, importante instrumento de concretização dos objetivos constitucionais da erradicação da pobreza e da redução das desigualdades sociais.

Palavras-chave: Assistência Social. Requisitos Benefício de Pres-

1 Data de recebimento: 30/06/2018. Data de aceite: 21/09/2018.

2 Graduado em Direito pela Universidade de Fortaleza. Advogado. E-mail: wagnerroadv@gmail.com 
tação Continuada. Análise Jurisprudencial de Requisitos do LOAS.

\section{INTRODUÇÃO}

Desde os primórdios, as desigualdades sociais fizeram parte de toda evolução civilizatória da humanidade. Dessa forma, essa realidade não poderia ser diferente no Brasil. Historicamente, a colonização do país se deu por intermédio da burguesia portuguesa, que obtinha lucros por meio da cultura do plantio, o que, para tanto, necessitava de mão de obra escrava, fazendo com que uma grande população africana fosse trazida para cá com este fim. Com o fim da escravidão, em 1888, e o aumento emigratório de pessoas de classes inferiores portuguesas para nossa nação, entre outros povos, essas desigualdades se tornaram mais frequentes e visíveis a cada passo evolucionário que era dado, tendo em vista que toda a legislação de amparo criada - e assim o é ainda nos dias atuais - se destinava à burguesia dominante.

Nesse viés é que foi consagrado, no contexto da Constituição Brasileira de 1988, como forma de objetivos garantidores de erradicação da pobreza e das diferenças sociais (artigo $3^{\circ}$ ), o dever constitucional social, juridicamente imposto, de amparar o idoso com mais de 65 anos de idade e a pessoa com deficiência, principalmente, ao se entender que estas se encontram sem condições de prover sua própria manutenção, ou sequer podem tê-la provida por familiares, uma vez que se encontram diante de barreiras que os impedem de participar de forma plena e efetiva na sociedade em condições igualitárias às demais pessoas.

Diante de toda a problematização social que acometia essas pessoas, e diante do que foi consagrado no artigo 203 da Constituição Federal de 1988, o Legislativo, ao perceber as necessidades que deficientes e idosos apresentavam, resolveu criar o Benefício de Prestação Continuada, abrangido como uma prestação de caráter 
assistencial, estando incurso na Assistência Social, dentro do leque de abrangências da Seguridade Social, com a finalidade de amenizar as desigualdades que os acometiam, procedendo, para tanto, na criação da Lei Orgânica de Assistência Social (Lei no 8.742/93), conhecida como LOAS.

Entretanto, a regulamentação dos requisitos para a efetivação do artigo 203 da Constituição, por si só, não foi suficiente para pôr fim a este impasse social. Logo se iniciaram discussões a respeito da inconstitucionalidade do $\S 3^{\circ}$ do artigo 20 da referida lei, o qual diz respeito ao critério de aferição da miserabilidade do requerente para concessão do benefício, instituindo que a renda máxima familiar per capita não poderá ultrapassar 1 /4 do salário mínimo vigente.

Entendeu-se, e se entende até os dias atuais, que a renda máxima per capita de $1 / 4$ do salário mínimo exigida pela Lei representa óbice à efetivação da intenção constitucional de erradicar as desigualdades sociais, visto que deixa de envolver todas as situações fáticas causadoras das desigualdades sociais no país.

Verificada toda essa problemática em torno desse requisito para constatação da miserabilidade da pessoa deficiente e idosa, foram intentadas duas ações com maior repercussão acerca da discussão sobre o tema: a Ação Direta de Inconstitucionalidade $\mathrm{n}^{\circ}$ 1.232-1/DF e, recentemente, a Reclamação n 4.374/2013 do Estado de Pernambuco.

\section{DA SEGURIDADE SOCIAL}

O conceito de Seguridade Social, embora pareça simples, detém certa dificuldade, visto sua carga histórica e sua evolução social. Assim, este conceito foi bem definido nas palavras de Martins (2007, p.19) como sendo o conjunto de princípios, regras e instituições destinados a criar um sistema de proteção social aos indivíduos contra contingências sociais, que os impeçam de prover suas necessidades 
pessoais básicas, assim como de suas famílias, integrado por ações de iniciativa dos Poderes Públicos e da Sociedade, visando a assegurar os direitos relativos à saúde, à previdência e à assistência social.

No Brasil, a Seguridade Social foi bem delimitada, nos moldes atuais, com o advento da Constituição Federal de 1988, que trouxe em seu bojo uma definição mais abrangente do conceito de seguridade social, visto seu enfoque social e cidadão. A mesma estabeleceu um sistema integrado de saúde, previdência e assistência social, estabelecendo benefícios e serviços a serem prestados pelo Poder Público, haja vista a necessidade de se estabelecer proteção aos segurados e às demais pessoas contra as contingências sociais, assim como ao impacto financeiro que estas, por ventura, possam representar.

A Seguridade Social constitui um conceito amplo que abrange a proteção a todos, sendo prestada a qualquer pessoa, independente de contraprestações diretas, ou exigência de enquadramento em certas condições, dependendo da área de atuação da previdência social. Vale destacar que, diferentemente da previdência social, onde essa prestação não se dará sem uma contraprestação prévia por parte do segurado, a saúde e a assistência social, de forma ampla, independerão dessas contraprestações, ao passo que a própria Constituição Federal, em seu Art. 203, garante a assistência a quem dela necessitar, e no seu Art. 196, institui que a saúde é direito de todos e dever do Estado.

Dessa forma, tem-se a previdência social, que tem por objetivo superar as contingências sociais que possam acometer o segurado, como doenças, incapacidades, ou até a morte, o que, neste último caso, compreende amparar os familiares, que por ventura dependiam do segurado para prover sua subsistência. Podemos ver esta percepção de forma acertada na visão de Lopes (2010, p. 12):

O conceito de previdência social relaciona-se com a vontade do homem, desde os tempos antigos, em prover seu futuro e de seus familiares, preocupando-se sempre em deixar condições mais confortáveis para os seus descen- 
dentes, bem como porque sabe que certos eventos como a velhice, as doenças e a morte são inevitáveis. A previdência abrange a proteção contra as contingências futuras, as quais podem ensejar situações de necessidade, carência de recursos suficientes para a sobrevivência digna.

Estando a República Federativa do Brasil, assim como a Constituição vigente, ancorados à Dignidade da Pessoa Humana, o Estado presta compromisso formal em assegurar o mínimo existencial aos seus cidadãos, dando-lhes uma vida digna por meio dos direitos sociais prestados pelas ações públicas de Seguridade Social, mais especificamente prestados pela Assistência Social. Sarlet (2006, p. 60) propôs uma conceituação jurídica para a dignidade da pessoa humana:

Temos por dignidade da pessoa humana a qualidade intrínseca e distintiva de cada ser humano que o faz merecedor do mesmo respeito e consideração por parte do Estado e da comunidade, implicando, neste sentido, um complexo de direitos e deveres fundamentais que assegurem a pessoa tanto contra todo e qualquer ato de cunho degradante e desumano, como venham a lhe garantir as condições existenciais mínimas para uma vida saudável, além de propiciar e promover sua participação ativa co-responsável nos destinos da própria existência e da vida em comunhão dos demais seres humanos.

Dessa forma é que se entende o papel de extrema importância de ter a Seguridade Social inserido a Assistência Social em seu âmbito de abrangência.

De igual modo, coaduna com esse pensamento garantista Sarlet e Marinoni (2015, p. 614), quando afirmam que a garantia efetiva de uma existência digna abrange, de acordo com a compreensão que prevalece, mais do que a garantia da mera sobrevivência física, não devendo buscar apenas a superação da pobreza absoluta e redução à mera existência física, ou seja, aquilo que alguns denominam como mínimo existencial fisiológico, mas se deve alcançar, também, a ga- 
rantia de um mínimo de integração social, bem como, de modo geral, acesso aos bens culturais e participação na vida política, aspectos que, segundo os autores, dizem respeito a um mínimo existencial sociocultural.

Embora maior destaque a esse contexto, a seguridade, como já mencionado, não é composto apenas pela previdência, ou seja, não tem caráter apenas contributivo. Por sua vez, a concepção distributiva não irá se embasar na realização de atividade laborativa, ou mesmo mediante contraprestações facultativas, visto seu caráter assistencialista pressupondo uma solidariedade natural, conforme as palavras de Costa (2005, p. 17):

Para a seguridade social distributiva, o fundamento do direito da própria seguridade social não se embasa no exercício de uma atividade profissional e no aporte de cada indivíduo para com a sociedade, mas se encontra nas suas necessidades, levando em conta a existência de uma solidariedade natural entre os membros da mesma coletividade.

A concepção distributiva manifesta-se, principalmente, por meio das áreas a saúde e da assistência, nas quais objetiva-se o amparo aos necessitados e a redução das desigualdades sociais, surgindo aqui uma solidariedade, intimamente ligado à distributividade. É a coletividade que, por meio das contribuições, custeia e cede uma parte de seus direitos individuais futuros para beneficiar a todos, principalmente àqueles que se encontram em um estado de extrema carência social.

\section{DO BENEFÍCIO DE PRESTAÇÃO CONTINUADA}

A Assistência Social, conforme já conceituada, consiste no sistema da seguridade destinado a qualquer pessoa que dela necessitar, independente de contraprestação prévia.

Segundo Ibrahim, citado por Balera (2008, p. 53 apud PEREIRA, 
2014, p. 81), a assistência social nasce de uma iniciativa mútua do Estado, tanto inicialmente quanto posteriormente, na qual, em primeiro plano, reúne integrantes que guardam entre si alguma forma de afinidade, como profissionais, religiosos, ou mesmo geográfica, enquanto em um segundo momento, esteve contida na iniciativa denominada "socorro mútuo", estabelecida dentro do contexto da Constituição Imperial de 1824, de acordo com os parâmetros da expressão tradicional da Revolução Francesa, desenvolvendo-se até o final do século XIX.

\subsection{Conceito}

O Benefício de Prestação Continuada (BPC), foi criado com o objetivo de sanar as desigualdades sociais que acometem a população do país, especificamente, aquelas pessoas atingidas por doenças incapacitantes de forma permanente e aquelas que atingiram 65 anos de idade, sem que tenham tido condições de exercer qualquer função pretérita a esta condição e, consequentemente, não verteram quaisquer ou suficientes contribuições para o sistema da previdência.

Desse modo, tendo por base o objetivo constitucional de erradicar a pobreza e as desigualdades sociais, enraizado no inciso III do artigo $3^{\circ}$ desta, foi conferido a esse nicho populacional específico um benefício no valor de um salário mínimo mensal, desde que o beneficiário atinja os requisitos para a concessão. Conforme previsão do artigo 203, inciso V, da Constituição Federal de 1988, criou-se a Lei $n^{\circ} 8.742$ de 1993, a qual se encarregou de regular a concessão dos benefícios de prestação continuada, estipulando, assim, quais requisitos deverão ser preenchidos.

Ainda, observa Somariva (2003, p. 797) que este benefício visa exclusivamente a que as pessoas com deficiência ou idosas, que não possuem os meios de prover sua subsistência ou tê-la provida por seus familiares, tenham condições de verem atendidas suas ne- 
cessidades mais básicas e urgentes, como alimentação e vestuário com o mínimo de dignidade, até que estas pessoas estejam aptas a exercer alguma função no mercado de trabalho.

Assim, pode-se dizer que o benefício de prestação continuada foi criado pelo Estado como forma de garantir a uma parcela distinta da população mais vulnerável, a seu ver, formas de obter um mínimo existencial, proporcionando igualdade de direitos a todos os cidadãos, efetivando, com isso, o princípio da dignidade da pessoa humana e, consequentemente, aproximando-se de ver concretizado, mesmo que em média escala, o objetivo constitucional da erradicação da pobreza e das desigualdades sociais no país.

\subsection{Previsão normativa}

A previsão normativa do referido benefício encontra-se na Constituição Federal de 1988, em seu artigo 203, inciso V, ao garantir à pessoa com deficiência e ao idoso, impossibilitados de prover sua própria subsistência, ou tela provida por seus familiares, o valor de um salário mínimo mensal, conforme dispuser a lei.

Desse modo, com base no mencionado artigo, foi criada a Lei $n^{\circ}$ 8.742, de 1993, que dispõe, detidamente em seu artigo 20, os requisitos para a concessão do benefício de prestação continuada.

\subsection{Critérios legais autorizadores da concessão}

Como se pode observar, a Lei $n^{\circ} 8.742 / 93$, detidamente em seu artigo 20, trouxe um rol com critérios legais para autorização da concessão do benefício assistencial de prestação continuada. Assim, tem-se que as pessoas com deficiência ou o idoso com 65 anos ou mais, farão jus à concessão se, para a pessoa com deficiência, esta condição incapacitante for considerada de longo prazo, compreendida como de natureza física, intelectual e sensorial, a qual, em 
interação com uma ou mais barreiras, pode obstruir sua participação plena e efetiva na sociedade em igualdade de condições com as demais pessoas ( $\S 2^{\circ}$ do artigo 20 da Lei), sendo considerada para fins de condição incapacitante de longo prazo aquela que perdurar pelo prazo mínimo de 2 anos (§ 10).

Em relação a ambos, deve restar comprovada a situação fática da condição de impossibilidade dessas pessoas em suprir seu próprio sustento, ou de tê-lo suprido por seus familiares (caput), sendo considerado, para efeitos dessa impossibilidade, a família com renda per capita inferior a $1 / 4$ do salário mínimo vigente $\left(\S 3^{\circ}\right)$.

Diante disso, mostra Barros Júnior (2010, p. 196-197) que a comprovação da renda se dará mediante Declaração de Composição e Renda Familiar, em formulário instituído para esse fim, assinado pelo requerente do benefício, ou por seu representante legal, confrontada com os documentos pertinentes, ficando o declarante sujeito às penas previstas por falsidade ideológica ou declaração falsa. As pessoas que não possuem renda, ou que estejam impossibilitadas de comprovar sua renda, devem informar sua situação de rendimento na referida declaração.

\subsubsection{Do Critério de aferição da miserabilidade}

Como já dito, a condição de miserabilidade será demonstrada pela renda per capita familiar, que não deverá ultrapassar 1/4 do salário mínimo vigente.

Dito isso, a problemática em torno do requisito para constatação da miserabilidade da pessoa com deficiência e idosa deu origem a duas emblemáticas ações como o fulcro de se discutir a flexibilização ou não do requisito mencionado, à Ação Direta de Inconstitucionalidade $n^{\circ}$ 1.232-1/DF, e, em 2013, foi levado a julgamento perante o Supremo Tribunal Federal a Reclamação 4.374/PE, que também buscou analisar o critério de aferição da miserabilidade em sem pa- 
tamar de 1/4 aplicável em todos os casos de concessão do benefício de prestação continuada, sendo certo que o julgamento dessa última reclamação trouxe diversas mudanças positivas.

Deve-se ressaltar que a abordagem acerca desses julgados de forma mais aprofundada será feita no próximo capítulo.

\section{ANÁLISE JURISPRUDENCIAL: FLEXIBILIZAÇÃO DO CRITÉRIO LEGAL DA RENDA}

O capítulo anterior fez uma sucinta abordagem acerca do Benefício de Prestação Continuada, detidamente no que se refere a seus moldes conceitual e legal. Viu-se, também, os critérios utilizados pela Lei $n^{\circ} 8.742 / 93$ para concessão do referido benefício àquele que pretender requerê-lo, seja na seara administrativa, seja na seara judicial.

Entretanto, garantir esse benefício está longe de ser uma solução eficaz para concretização dos objetivos mencionados, tendo em vista que o próprio significado da palavra "eficaz" remete à ideia de algo que obtêm êxito, que é concluído com sucesso. E como se sabe, ou não, o Estado se vale do princípio da eficiência administrativa, ou seja, fará aquilo da "melhor maneira possível", visto que é improvável que este detenha plenas condições de concretização dos objetivos. Dito isso, é que se pode falar das divergências doutrinárias e jurisprudenciais que cercam a concessão do Benefício de Prestação Continuada de forma geral, recaindo sobre o requisito da miserabilidade a maior gama de discussões.

O artigo 20, parágrafo $3^{\circ}$, da Lei $n^{\circ} 8.742 / 93$ estipulou que a família será considerada incapaz de prover a manutenção do idoso e da pessoa com deficiência, se a renda mensal per capita for inferior a 1/4 do salário mínimo vigente à época do requerimento. A discussão se instaurou justamente nesse quantitativo de $1 / 4$, visto que muitos consideram esse valor-base como um verdadeiro "entrave social" à concretização dos objetivos de erradicação da pobreza e das desi- 
gualdades sociais vislumbradas pela constituição.

Dessa forma, deve-se dar maior notoriedade a duas discussões jurisprudenciais especificas, responsáveis por difundir as divergências em torno do requisito mencionado, haja vista ter dado início a duas linhas de pensamentos antagônicas na aplicação deste requisito pelo Judiciário pátrio. Assim, tem-se, inicialmente, a Ação Direta de Inconstitucionalidade $\mathrm{n}^{\circ}$ 1.232-1/DF, tendo como relator o Ministro Ilmar Galvão; e a Reclamação 4.374/PE, tendo como relator o Ministro Gilmar Mendes, a qual buscou analisar o critério de aferição da miserabilidade em sem patamar de $1 / 4$, onde se encontra a maior carga de importância dessa discussão, tendo em vista que rediscutiu o entendimento proferido na ADI, mudando completamente o entendimento pretérito do Supremo Tribunal Federal.

\subsection{A Ação Direta de Inconstitucionalidade no 1.232-1/DF}

Conforme mostrado anteriormente, muito se discutiu no âmbito de Supremo Tribunal Federal a respeito do critério objetivo de 1/4 do salário mínimo per capita utilizado pelo parágrafo $3^{\circ}$, do artigo 20, da Lei $n^{\circ} 8.742 / 93$. Nesse ponto, se faz vênia tecer uma breve análise individualizada de dois julgados tidos como destaques entre todos: A Ação Direita de Inconstitucionalidade $\mathrm{n}^{\circ}$ 1.232-1/DF e a Reclamação n 4.374/PE.

De relatoria do Ministro Ilmar Galvão, este defendeu que o mencionado parágrafo não é inconstitucional, argumentando que a Lei, ao instituir que a aferição da miserabilidade do idoso e da pessoa com deficiência seriam aferidos levando-se em consideração que a renda mensal per capita não ultrapasse 1/4 do salário mínimo vigente. Afirmou que, embora o texto legal tenha tratado de uma forma objetiva de requisito, esta, por sua vez, não limita a comprovação da miserabilidade da pessoa com deficiência e do idoso.

Ao ser a demanda julgada no Pleno em 27 de agosto de 1998, a 
Procuradoria-Geral da República restou vencida, onde o relator julgou procedente a ação, em parte, para o efeito de seu voto. Acompanharam-no os Ministros Nelson Jobim, afirmando que "compete a Lei dispor a forma da comprovação. Se a legislação resolver criar outros mecanismos de comprovação, é problema da própria lei"; Ministro Maurício Corrêa, acompanhando o anterior; O Ministro Sepúlveda Pertence, onde declarou que "o legislador deve estabelecer outras situações caracterizadoras da absoluta incapacidade de manter-se o idoso ou o deficiente físico, a fim de completar a efetivação do programa normativo de assistência contido no art. 203 da Constituição" (sic). Ainda afirmou de forma expressiva que:

A meu ver, isso não a faz inconstitucional nem é preciso
dar interpretação conforme à lei que estabeleceu uma
hipótese objetiva de direito à prestação assistencial do
Estado. Haverá, aí, inconstitucionalidade por omissão de
outras hipóteses? A meu ver, certamente sim, mas isso
não encontrará remédio nesta ação direta. (1998, p. 105).

Este julgamento, conforme já abordado anteriormente, conferiu ao cerne da questão uma interpretação concretista do texto legal objetivo, de forma que, até meados do ano de 2005, esta interpretação foi utilizada com muito rigor na grande maioria dos julgamentos envolvendo o tema.

\subsection{Da flexibilização do critério de aferição de renda e a Re- clamação no 4.374/2007}

Passa-se, agora, a uma breve síntese a respeito da flexibilização dessa aferição e do que foi decidido em sede de Reclamação $n^{\circ}$ $4.374 / 2007$.

Diante de tudo isso, o Juízo Especial Federal, na maioria de suas decisões, adotou a forma de concessão do benefício levando-se em consideração outros meios de comprovação da condição de misera- 
bilidade exigido pela Lei no 8.742/93, baseando-se no surgimento de novas Leis que tratavam de concessão de benefícios assistenciais, as quais traziam, a exemplo, a consideração, para fins de aferição da miserabilidade, a família com renda per capita de 1/2 salário mínimo, extraído de algumas Leis, a exemplo da n 10.219/2001, que criou a Bolsa Escola.

Não menos importante, Dias e Macêdo (2012, p. 399-400) lembram a Súmula no 11 da Turma de Nacional de Uniformização, órgão responsável por firmar entendimentos reiterados no âmbito dos Juizados Especiais Federais, declarava em seu teor que "a renda mensal, per capita, familiar, superior a 1/1/4 (um quarto) do salário mínimo, não impede a concessão do benefício assistencial previsto no art. 20, § $3^{\circ}$ da Lei n ${ }^{\circ} .8 .742$ de 1993, desde que comprovada, por outros meios, a miserabilidade do postulante". Entretanto, esta Súmula restou cancelada pelo órgão, em sede de julgamento do Pedido de Uniformização no 2004.70.95.009545-6/PR, de relatoria do Juiz Federal Hélio Silvio Ourem Campos, rendendo-se ao posicionamento concretista do Supremo Tribunal em julgamento da ADI no 1.232/DF.

Assim, embora a Súmula $\mathrm{n}^{\circ} 11$ da Turma de Nacional de Uniformização não tenha vigorado, o entendimento da flexibilização não deixou de ser utilizado pelo Judiciário de maneira geral e, por esta prática recorrente, chegou ao Supremo Tribunal Federal a Reclamação $n^{\circ}$ 4.374/PE, de 01 de fevereiro de 2007, oriunda do julgamento prévio dos Recursos Extraordinários no 580.963 e 567.985, definido como relator o Ministro Gilmar Mendes, o qual definiu a questão como "uma soma de injustiças, decorrente de uma desencontrada relação entre letra objetiva da lei e a vontade da Constituição".

O Ministro Gilmar Mendes se baseou na análise do advento das Leis $n^{\circ}$ 10.836/2004, que criou o Bolsa Família, a Lei nº 10.689/2003, que instituiu o Programa Nacional de Acesso à Alimentação; a Lei ${ }^{\circ}$ 10.219/01, que criou o Bolsa Escola, n 9.533, que autoriza o Poder Executivo a conceder apoio financeiro a municípios que instituírem 
programas de garantia de renda mínima associados a ações socioeducativas, e tendo por base o comportamento reiterado dos Juízes Federais em conceder o Benefício de Prestação Continuada. Em muitos casos, foi utilizado os critérios de miserabilidade dessas Leis, por serem mais flexíveis aos postulantes de requerimentos via judicial.

Decidiu, por fim, pela declaração parcial de inconstitucionalidade sem redução de texto do parágrafo em questão, haja vista a decisão proferida em sede de ADI n 1.232 -1 não ter limitado a interpretação extensiva do referido parágrafo para conceder o benefício assistencial o que, sem sombra de dúvidas, vem como forma eficiente de realização dos objetivos consagrados pela Constituição Federal em seu artigo 203.

Dessa forma, reconheceu-se a possibilidade de os juízes, nos casos concretos, poderem aferir a miserabilidade com base em outros requisitos. Posteriormente, foi realizada alteração na Lei no 8.742/1993, efetuada pela Lei $n^{\circ} 13.146 / 2015$, que acrescentou o $\S 11$ ao art. 20 do diploma citado, com o objetivo de prever que regulamento, ainda não editada, poderá estabelecer outros elementos probatórios da condição de miserabilidade do grupo familiar e da situação de vulnerabilidade. Esse reconhecimento representou a efetivação dos direitos sociais fundamentais, como um mínimo de segurança social, conforme apontado por Amaral (2014, p.459):

A efetivação dos direitos sociais fundamentais não se reduz à garantia do mínimo existencial, esse deve ser compreendido como garantia fundamental, como um mínimo de segurança social cujo conteúdo é flexível, variável, devendo-se analisar a necessidade de cada pessoa e o contexto familiar, social, econômico, cultural no qual está inserida, compreendido como condições basilares para uma existência com dignidade.

Conforme visto, o julgamento da Reclamação n 4.374/2013 foi de suma importância para o avanço da concretização das políticas de erradicação da pobreza e das desigualdades sociais idealizadas 
pela Constituição Federal de 1988. Acima disso, representou um marco ao efetivar de forma mais eficiente o que fora idealizado pela Declaração Universal dos Direitos Humanos, em seu artigo 22, e pelo Pacto Internacional sobre os Direitos Econômicos, Sociais e Culturais, em seu artigo $9^{\circ}$, os quais versam sobre a Seguridade Social em um âmbito Internacional. Veja-se, abaixo, o que foi instituído por ambos:

\begin{abstract}
Artigo XXII
Todo ser humano, como membro da sociedade, tem direito à segurança social, à realização pelo esforço nacional, pela cooperação internacional e de acordo coma organização e recursos de cada Estado, dos direitos econômicos, sociais e culturais indispensáveis à sua dignidade e ao livre desenvolvimento da sua personalidade.

Artigo $9^{\circ}$.

Os Estados Partes no presente Pacto reconhecem o direito de todas as pessoas à segurança social, incluindo os seguros sociais.
\end{abstract}

\title{
5 CONCLUSÃO
}

A evolução do entendimento jurisprudencial no Brasil, acerca da temática de concessão do Benefício de Prestação Continuada, sendo este uma garantia da consolidação da Assistência Social, prevista no artigo $6^{\circ}$ da Constituição de 1988, tem contribuído para o combate e diminuição da pobreza e das desigualdades sociais no país, sendo certo que a população idosa e deficiente é a que mais sofre com essas desigualdades, ao passo que o Estado, muitas vezes, não a ampara a contento.

Diante disso, sendo certo que o legislador, na Lei 8.742 de 1993, apenas atribuiu um requisito de significado objetivo, deixando de levar em consideração todas as demais situações fáticas que acometem aqueles que postulam o requerimento de concessão do benefício nas vias administrativas. Desse modo, recaiu sobre o Supremo Tribunal Federal a tarefa atípica de, indiretamente, legislar sobre aquilo que restou lacunoso, utilizando-se de suas prerrogativas de interpretador 
hermenêutico constitucional, a fim de dar novo entendimento ao dispositivo criado.

Não se pode falar em uma Lei extremamente abrangente, haja vista a imparável mutação social que ocorre diariamente, situações em que se exige do Legislativo mudanças periódicas de curto tempo de apreciação. Como bem se sabe, ou não, a mudança ou criação de legislações que possam acompanhar essas mudanças, em tempo real, são praticamente impossíveis, uma vez que todo o processo legislativo a que se submete uma Lei é bastante complexa e dependente de um pensamento igualitário por parte da maioria dos legisladores.

Nesse viés é que foi julgada a Reclamação n 4.374/PE, entendo que a legislação, objetiva, não seria capaz de abranger todas as situações fáticas dos casos concretos e, ao fim, tendo decidido pela declaração parcial de inconstitucionalidade sem redução de texto do parágrafo 30 ${ }^{\circ}$ do artigo 20, da Lei no 8.742/1993, sob a alegação de que a decisão concretista adotada em sede de julgamento da ADI $n^{\circ}$ 1.232/DF não tinha limitado a utilização de outros meios de provas para aferição do requisito da miserabilidade, uma vez que esta decisão decidiu apenas sobre a constitucionalidade do referido parágrafo.

Entretanto, muito ainda precisa ser feito, por parte do Estado, para que as pessoas em situação de vulnerabilidade, em especifico, as pessoas com deficiência e o idoso, consigam ter, definitivamente, condições igualitárias no meio social em que vivem.

Por tudo isso, é que se chega à conclusão de que o Estado, diante de sua figura legislativa, deve se utilizar dos elementos de flexibilização e amparo já disponíveis, alterando, decerto, a Lei no 8.742/1993, inserindo em seu texto medidas que visem de forma concreta, à (re) inserção dos beneficiários do Benefício de Prestação Continuada, uma vez que, acima de qualquer raciocínio lógico legal, essa medida assistencialista tem um viés constitucional garantista do Princípio maior que a rege, o da Dignidade da Pessoa Humana, e, dessa maneira, o Estado deve buscar garantir-lhes, não apenas mera forma 
de subsistência, mas, sobretudo, uma vida digna sem ansiar pelo socorro estatal, cheia de felicidades, condições de usufruir de um bom serviço de saúde e educação, entre outras garantias previstas no texto pela própria Constituição Federal de 1988 em seu artigo $6^{\circ}$.

\section{THE ANALYSIS OF THE PERSONAL CONDITIONS OF THE INTERESTED PARTY IN THE RECOGNITION OF THE NEED FOR THE CONTINUED BENEFIT OF BENEFIT}

\section{ABSTRACT}

When carrying out the work on the proposed theme, initially a brief approach is made to the concept of Social Security. Next, an explanation is given about the Continuous Benefit Benefit, as part of the measures adopted by the State in the Social Assistance area, conceptualizing it, indicating its legal prediction and presenting a briefintroduction on the subject regarding the criterion of measurement of miserability, focus of this work. Finally, a descriptive analysis of the legal precedents of the country in the scope of the Federal Supreme Court on the requirement of miserability is made, considering the wide critical-doctrinal development involving the subject matter, and how this discussion was developed until one arrives at a flexible thought of this requirement in question. After this explanation, we conclude by analyzing the importance of the emergence of new legislative measures, with the purpose of improving the lives of people with disabilities and the elderly person over 65 in society, on equal terms with other people, an important instrument for achieving the constitutional objectives of eradicating poverty and reducing social inequalities.

Keywords: Social assistance. Requirements Continuous Benefit Benefit. Jurisprudential Analysis of LOAS Requirements. 


\section{REFERÊNCIAS}

BARROS JÚNIOR, Edmilson de Almeida. Direito previdenciário médico: benefícios por incapacidade laborativa e aposentadoria especial. São Paulo: Atlas, 2010.

BRASIL. Lei $\mathbf{n}^{\circ}$ 10.741, de 01 de outubro de 2003. Disponível em: <http:// www.planalto.gov.br/ccivil_03/leis/2003/L10.741.htm> Acesso em: 23 abr. 2017.

Constituição Federal de 1988. Promulgada em 5 de outubro de 1988. Disponível em: <http://www.planalto.gov.br/ccivil_03/constituicao/ constituição.htm> Acesso em: 23 maio 2017.

Lei $\mathbf{n}^{\circ}$ 13.146, de 06 de julho de 2015. Disponível em: <http:// www.planalto.gov.br/ccivil_03/_ato2015-2018/2015/lei/113146.htm> Acesso em: 23 maio 2017.

Lei no 8.472, de 07 de dezembro de 1993. Disponível em: <http:// www.planalto.gov.br/ccivil_03/leis/L8742.htm> Acesso em: 23 maio 2017.

Supremo Tribunal Federal. Ação Direta de Inconstitucionalidade n. 1.232/DF. Relator Ministro Ilmar Galvão. Ementário n. 2033-1. Diário da Justiça 10.6.2001. Disponível em: <http://redir.stf.jus.br/paginadorpub/paginador.jsp?docTP=AC\&docID=385451 >. Acesso em: 21 maio 2017.

Supremo Tribunal Federal. Reclamação n. 4.374/PE. Relator Ministro Gilmar Mendes. Diário da Justiça Eletrônico - 173 4.9.2013. Disponível em: < https://stf.jusbrasil.com.br/jurisprudencia/24806757/reclamacao-rcl-4374-pe-stf>. Acesso em: 22 maio 2017.

COSTA, Valéria de Fátima Izar Domingues da. Um paralelo sobre a aposentadoria, por idade, dos trabalhadores: urbano e rural. São Paulo: Pontifícia Universidade Católica, 2005. Disponível em: <https://sapientia. pucsp.br/bitstream/handle/5621/1/Dissertacao\%20Valeria\%20F\%20Izar\%20 D\%20da\%20Costa.pdf>. Acesso em: 20 mar. 2017.

DIAS, Eduardo Rocha; MACÊDO, José Leandro Monteiro de. Curso de direito previdenciário. 3. ed. Rio de Janeiro: Forense, 2012.

LOPES, Cinara Cecília Mendonça. Proteção Previdenciária na União Estável e no Concubinato. Fortaleza, UNIFOR, 2010, 71p. Monografia (Graduação em Direito). Centro de Ciências Jurídicas, Universidade de Fortaleza, 2010. 
MARTINS, Sérgio Pinto. Direito da Seguridade Social. 24. ed. São Paulo: Atlas, 2007.

ORGANIZAÇÃO DAS NAÇÕES UNIDAS. Declaração Universal de Direitos Humanos, Viena, de 10 de dezembro de 1948. Disponível em: <http://www. planalto.gov.br/ccivil_03/_Ato2007-2010/2007/Decreto/D6214.htm> Acesso em: 21 abr. 2017.

PEREIRA, Caroline Quadros da Silveira. Benefício Assistencial de Prestação Continuada - O Conceito de Família. Revista Síntese: direito de família. São Paulo, v. 15, n. 84, p. 79-94, jun./jul.2014.

SARLET, Ingo Wolfgang. Dignidade da pessoa humana e direitos fundamentais na constituição federal de 1988. 4. ed. rev. Atual. Porto Alegre: Livraria do Advogado, 2006.

SARLET, Ingo Wolfgang; MARINONI, Luiz Guilherme; MITIDIERO, Daniel. Curso de direito constitucional. 4. ed. ampl., incluindo novo capítulo sobre princípios fundamentais. São Paulo: Saraiva, 2015.

SOMARIVA, Maria Salute. O Benefício de amparo assistencial como garantia das necessidades básicas do cidadão carente. Revista de previdência social. São Paulo, v. 27, n. 274, p. 796-798, set. 2003. 